GRASAS Y ACEITES 68 (2)

April-June 2017, e194

ISSN-L: 0017-3495

doi: http://dx.doi.org/10.3989/gya.1168162

\title{
Cold pressed versus refined winterized corn oils: quality, composition and aroma
}

\author{
B. Aydeniz Güneşer ${ }^{\mathrm{a}, \mathrm{b}}$, E. Yılmaz ${ }^{\mathrm{a}, 凶}$ and S. Ok ${ }^{\mathrm{a}}$ \\ ${ }^{a}$ Çanakkale Onsekiz Mart University, Faculty of Engineering, Department of Food Engineering, 17020, Çanakkale, Turkey \\ ${ }^{b}$ Uşak University, Faculty of Engineering, Department of Food Engineering, Uşak, Turkey \\ ${ }^{\square}$ Corresponding author: eyilmaz@comu.edu.tr
}

Submitted: 24 November 2016; Accepted: 06 March 2017

SUMMARY: The aims of this study were to characterize and compare cold pressed and fully refined winterized corn oils. Free fatty acidity (FFA), peroxide (PV) and $p$-anisidin $(p-\mathrm{AV})$ values, saponification number, total carotenoid and phenolic contents of cold pressed corn oils were higher than that of the refined winterized corn oils. Linoleic and oleic acids (approximately 53-54\% and 30-31\%, respectively) were detected as the major fatty acids in both oil samples. Fifteen different sterols with a majority of $\beta$-sitosterol, campesterol, and stigmasterol were quantified in both oil samples. Although phenolic compounds were not quantified in the refined winterized oil samples, some flavonoids (hesperidin, rutin) and phenolic acids (gallic, syringic, rosmaniric and trans-ferulic) were detected in the cold pressed oil samples. This study concludes that cold pressed corn oils could be superior in terms of bioactive compounds but still need some quality improvements for sensory attributes.

KEYWORDS: Cold pressing; Corn oil; Nutrition; Refining; Sensory; Volatile

RESUMEN: Aceites de maiz prensados en frío Vs. refinado y winterizado: calidad, composición y aroma. Los objetivos de este estudio fueron caracterizar y comparar los aceites de maíz prensados en frío y los totalmente winterizados y refinados. Los valores de acidez libre (FFA), peróxidos (PV) y p-anisidina (p-AV), índice de saponificación, contenido total de carotenoides y compuestos fenólicos de los aceites de maíz prensados en frío fueron superiores a los de los aceites de maíz refinados. Los ácidos linoleico y oleico (aproximadamente 53-54\% y $30-31 \%$, respectivamente) fueron los ácidos grasos mayoritarios en ambas muestras de aceite. Quince esteroles diferentes fueron cuantificados en ambos aceites siendo los mayoritarios $\beta$-sitosterol, campesterol y estigmasterol. Aunque los compuestos fenólicos no se cuantificaron en las muestras refinadas de aceites winterizados, se detectaron algunos flavonoides (hesperidina, rutina) y ácidos fenólicos (gálico, siríngico, rosmarínico y transferúlico) en muestras de aceite prensado en frío. En este estudio se concluye que los aceites de maíz prensados en frío podrían ser superiores en términos de compuestos bioactivos, pero todavía necesitan algunas mejoras de calidad para los atributos sensoriales.

PALABRAS CLAVE: Aceite de maiz; Nutrición; Prensado en frio; Refinación; Sensorial; Volátil

ORCID ID: Aydeniz Güneşer B http://orcid.org/0000-0003-2197-5504, Ok S http://orcid.org/0000-0002-4257-6097, Yilmaz E http://orcid.org/0000-0003-1527-5042

Citation/Cómo citar este artículo: Aydeniz Güneşer B, Y1lmaz E, Ok S. 2017. Cold pressed versus refined winterized corn oils: quality, composition and aroma. Grasas Aceites 68 (2), e194. http://dx.doi.org/10.3989/gya.1168162

Copyright: (C) 2017 CSIC. This is an open-access article distributed under the terms of the Creative Commons Attribution (CC-by) Spain 3.0 License. 


\section{INTRODUCTION}

Corn or maize (Zea mays L.) is botanically an annual plant belonging to the grass (Poaceae) family. It originated in Mesoamerica, and is currently cultivated all over the world. The major corn producing countries are United States, China, Brazil, Mexico, Indonesia, India, France and Argentina. It was indicated that in 2016, 1.01 billion metric tons of corn were produced and more than 159 million hectares were used for corn cultivation. It was also indicated that production continually increases each year (Strecker et al., 1996; Anonymous, 2015a). In 2014, total corn and corn oil production in Turkey reached 64.618 tons and 20.362 tons, respectively (Anonymous, 2015b).

Corn is cultivated mainly for its starch and protein. Corn oil is a byproduct of starch processing, and obtained from corn germs. Corn contains approximately $61-78 \%$ starch, $6-12 \%$ protein, and $3.1-5.7 \%$ oil. As the oil source, the corn germ is separated from the kernel in a dry or wet milling process for starch production. Most of the time, a wet milling process is used for corn germ collection to extract the oil. Usually, corn oil is extracted from the germ via expeller pressing combined with hexane or isohexane extraction to get around $97-99 \%$ recovery yield. Crude corn oil is usually fully refined by alkaline refining, bleaching, de-waxing and deodorization processes (Strecker et al., 1996; Codex Stan, 2015).

The main fatty acid composition of corn oil is specified as $59.8 \%$ linoleic acid, $25.8 \%$ oleic acid, $11.0 \%$ palmitic acid, $1.7 \%$ stearic acid, and $1.1 \%$ linolenic acid. A more detailed fatty acid composition range data is also available: myristic acid $<0.1 \%$, palmitic acid $8.0-19.0 \%$, palmitoleic acid $<0.5 \%$, stearic acid $0.5-4.0 \%$, oleic acid $19.0-50.0 \%$, linoleic acid $34.0-62.0 \%$, linolenic acid $0.1-2.0 \%$, arachidic acid $<1.0 \%$, gadoleic acid $<0.5 \%$ and behenic acids $<0.5 \%$. It was indicated that deodorized corn oil contains $0.08-0.12 \%$ of total tocopherols which consist of $70-80 \% \gamma-, 20-25 \% \alpha$ - and 3-5\% $\delta$-tocopherols. Likewise, around $1.3-2.3 \%$ unsaponifiable matter is present, and around $60 \%$ of it are sterols. The predominant sterols were $\beta$-sitosterol, campesterol and stigmasterol. The ranges of tocopherols for corn oil are given as, $\alpha$-tocopherol $116-172 \mathrm{ppm}, \beta$-tocopherol 0-22 ppm, $\gamma$-tocopherol 1119-1401 ppm, and $\delta$-tocopherol 59-65 ppm. The most important physical properties of corn oil were also given as: iodine value of 118-133, saponification number of 187-193, refractive index of 1.470-1.474, unsaponifiable content of $1.3-2.3 \%$, titer of $14-20^{\circ} \mathrm{C}$, melting point of -12- (-10) ${ }^{\circ} \mathrm{C}$, and solidification point of -1.0- (-20.0) ${ }^{\circ} \mathrm{C}$ (Strecker et al., 1996; O’Brien, 2004).

The Cold press method for oilseeds and kernels is currently gaining attention for its special oil. There are supercritical extraction and solvent extraction methods in addition to regular expeller pressing to obtain oil, but each technique has its own advantages and drawbacks. The most important differences among the extraction techniques are mostly related to oil yield and the minor component compositions of the oil. Thereby, oils extracted by different techniques usually have different end points for use; some must be fully refined, while some could be used directly for edible, cosmetic or other purposes. Cold pressing is an easy, rapid, environmentally friendly, and cheap process which yields good quality oil, but it is poor in overall oil yield. Hence, it is only preferable when special purpose oils are demanded. Furthermore, there are strict requirements for producing acceptable grade coldpress oil. First, the seed or kernel must be very clean, homogeneous and free from all unacceptable contaminations. Then the extraction process must be under mild conditions (no heating, solvent or other chemicals). Finally, the cold pressed oils must be of edible grade regarding physicochemical and sensory properties, and must be safe. Under these circumstances, cold pressed oils could be very beneficial for human health, and could have exceptional aroma. Cold pressed oils do not contain traces of hexane or other solvents, and retain most of their bioactives components (tocopherols, sterols, phenols etc.) to make them highly valued products (Khoddami et al., 2014; Y1lmaz et al., 2015b).

The aim of this study was to compare cold pressed and fully refined winterized corn oils for their main physicochemical properties, nutrient composition, aromatic composition and consumer preferences for the first time in the literature. Another objective was to determine whether corn germs could be cold pressed to retain the highest amount of nutrients in the oil with acceptable aromatic composition and sensory properties.

\section{MATERIALS AND METHODS}

\subsection{Materials}

Corn germs $(5.9 \%$ moisture, $42.6 \%$ oil by dry basis) as clean and dry material were sampled (2 batches of samples, $5 \mathrm{~kg}$ each) for this study from the oil production line of a commercial facility (Cargill, Bursa, Turkey) and were gifted to us. From the same production line, refined winterized corn oil samples ( 2 samplings, $1 \mathrm{~kg}$ each) were also gifted to us. All chemicals used were analytical or chromatographic grade and purchased from Merck Co. (Darmstadt, Germany) and Sigma Chem. Co. (St. Louis, USA). The internal standards used in the chromatographic analyses were purchased from Supelco (Bellefonte, PA, USA), Nu-Check (Elysian, MN, USA) and Sigma Chem. Co. (St. Louis, USA). 


\subsection{Cold pressing of the corn germs}

The moisture content of the corn germs was adjusted to $12 \%$ by water conditioning (Aydeniz et al., 2014; Y1lmaz et al., 2015a) before cold pressing, since that moisture level was determined as the best point for maximum oil yield and ease of the operation by the pre-experiments. The prepared corn germs were cold pressed with a laboratory scale cold press machine $(12 \mathrm{~kg}$ seed/h capacity, single head, $2 \mathrm{hp}, 1.5 \mathrm{kw}$ power, Koçmaksan ESM 3710, İzmir, Turkey) in two separate batches for the 2 replicates of the study. The cold pressing machine was operated at $30 \mathrm{rpm}$ screw rotation speed, 10 mm exit die and $\max 40^{\circ} \mathrm{C}$ oil exit temperature. The cold pressed oils were first filtered through a filter bag which captures micron size particles (Miroil RB22Fs, Allentown, USA) to separate suspended materials and then centrifuged in a refrigerated centrifuge (Sigma 2-16 K, Postfach, Germany) at $6797 \mathrm{xg}$ for $10 \mathrm{~min}$ at room temperature. The obtained clear oil was weighed and placed into amber colored glasses, flushed with nitrogen and stored in a fridge during the analyses.

\subsection{Physical analyses of the corn oils}

The refractive indices of the oil samples were measured with Abbe 5 (Bellingham and Stanley, UK) refractometer at $25^{\circ} \mathrm{C}$. Apparent viscosity values were assessed by a Brookfield Viscometer (model DV II+Pro with Rheocalc software, Brookfield Eng. Lab., Inc., MA, USA) with LV-SC4-18 spindle and $30 \mathrm{rpm}$ at $25^{\circ} \mathrm{C}$. The specific gravity and turbidity $\left(25^{\circ} \mathrm{C}\right)$ values of the oil samples were measured with the AOCS method Cc 10c-95 (AOCS Methods, 1997) and by a Hach 2100 AN Turbidimeter (USA), respectively. CIE color values ( $\mathrm{L}, \mathrm{a}^{*}$ and $\left.\mathrm{b}^{*}\right)$ of the oils were determined using a Minolta Colorimeter CR-400 (Minolta Camera Co., Osaka, Japan). The sediment contents of the oils were measured gravimetrically according to Dündar Emir et al., (2015).

\subsection{Chemical analyses of the corn oils}

The free fatty acid contents and acid values of the samples were determined according to the AOCS method Ca 5a-40 and Cd 3d-63 (AOCS Methods, 1997). The peroxide values and iodine numbers were measured by the AOCS methods Cd 8-53 and Cd 1-25 (AOCS Methods, 1997), respectively. The $p$-anisidine value was determined by AOCS method Cd 18-90 (AOCS Methods, 1997). The saponification numbers and amounts of unsaponifiable matter were evaluated by following method Tl 1a-64 (AOCS Methods, 1997) and by the ISO 3596 method (ISO Method 3596, 2000). Total phenolic content by Folin-Ciocalteu reagent and antioxidant capacity by the Trolox equivalent antioxidant capacity (TEAC) were analyzed according to a previously described technique (Aydeniz and Yilmaz, 2012). The carotenoid contents expressed as total carotenoid and zeaxanthin in the cold pressed and refined corn oils were measured using an UV-Visible Spectrophotometer (Agilent 8453, Waldbronn, Germany) at $445 \mathrm{~nm}$ and petroleum ether: acetone $(1: 1, \mathrm{v} / \mathrm{v})$ as solvent by a method based on Frankel et al., (2010). The chlorophyll content expressed as mg pheophytin-a per kg oil was measured in accordance with method 13i-96 (AOCS Methods, 1997).

\subsection{Fatty acids, sterols and tocopherols compositions of the corn oils}

The fatty acid methyl esters (FAMEs) were prepared according to method Ce 2-66 (AOCS Methods, 1997). The identification of the fatty acid methyl esters was performed by Gas Chromatograph (Agilent Technologies 7890B, Palo Alto, CA, USA) equipped with a HP 88 capillary column $(100 \mathrm{~m} \times 0.25 \mathrm{~mm}$ ID $\times 0.2 \mu \mathrm{m}, \mathrm{J} \& \mathrm{~W}$ Scientific Co, CA, USA) and a flame ionization detector (FID) (Agilent Technologies, Palo Alto, CA, USA). The GC experimental conditions were as follows; oven temperature: $120^{\circ} \mathrm{C}$ for $1 \mathrm{~min}, 175^{\circ} \mathrm{C}\left(10^{\circ} \mathrm{C} / \mathrm{min}\right)$ for $10 \mathrm{~min}, 210^{\circ} \mathrm{C}\left(5^{\circ} \mathrm{C} / \mathrm{min}\right)$ for $5 \mathrm{~min}$ and $230^{\circ} \mathrm{C}$ $\left(5^{\circ} \mathrm{C} / \mathrm{min}\right)$ for $5 \mathrm{~min}$; injection volume $1 \mu \mathrm{L}$, injector split ratio $1: 50$, flow rate $2 \mathrm{~mL} / \mathrm{min}$, carrier gas hydrogen, injector and the detector temperatures were 250 and $280^{\circ} \mathrm{C}$, respectively. Fatty acid methyl esters were quantified by co-chromatography with a FAME mixture (37-components, C4-C24, Supelco, Bellefonte, PA, USA).

The sterol compositions of the oil samples were evaluated by the ISO 12228 method (ISO Method $12228,1999)$. Sterol fractions separated on TLC after saponification of the oil samples were analyzed with Gas Chromatography (Agilent Technologies 7890B, Palo Alto, CA, USA) equipped with a flame ionization detector (FID) (Agilent Technologies, Palo Alto, CA, USA) and DB5 capillary column $(30 \mathrm{~m} \times 0.25 \mathrm{~mm}$ ID $\times 0.1 \mu \mathrm{m}, \mathrm{J} \& \mathrm{~W}$ Scientific Co, CA, USA). The analysis was performed under the following GC conditions: oven temperature: $60^{\circ} \mathrm{C}$ for $2 \mathrm{~min}, 60-220^{\circ} \mathrm{C}\left(40^{\circ} \mathrm{C} / \mathrm{min}\right)$ for $1 \mathrm{~min}, 220-310^{\circ} \mathrm{C}$ $\left(5^{\circ} \mathrm{C} / \mathrm{min}\right)$ for $30 \mathrm{~min}$, injection volume $1 \mu \mathrm{L}$, injector split ratio $1: 100$, flow rate $0.8 \mathrm{ml} / \mathrm{min}$ carrier gas hydrogen $(30 \mathrm{ml} / \mathrm{min})$, injector and the detector temperatures were 290 and $300{ }^{\circ} \mathrm{C}$, respectively. Phytosterol identification was achieved by comparing the relative retention times from samples with those of commercially available standards (cholesterol, brassicasterol, stigmasterol, $\beta$-sitosterol) under the same operating conditions.

The $\alpha$-Tocopherol contents of corn oil samples were determined by reverse-phase HPLC using an Shimadzu HPLC system (Shimadzu Corporation, Kyoto, Japan) fitted with a LC-20AT HPLC pump, 
a DGU-20A5R degasser, a CTQ-10ASVP column oven, a RF-20A diode array detector according to the procedure of Grilo Câmara et al., (2014) with minor modifications. $20 \mu \mathrm{L}$ samples $(0.15 \mathrm{~g}$ oil in $3 \mathrm{~mL}$ dichloromethane) were injected by an SIL20AHT auto sampler into the Inertsil ODS-3 column $(250 \mathrm{~mm} \times 4.6 \mathrm{~mm}$ ID $\times 5 \mu \mathrm{m}$, GL Sciences Inc., Japan). Isocratic elution was used with a flow rate of $1.6 \mathrm{~mL} / \mathrm{min}$. The mobile phase consisted of methanol: water $(98: 2 \mathrm{v} / \mathrm{v})$. Detector wavelengths were $290 \mathrm{~nm}$ for excitation and $330 \mathrm{~nm}$ for emission. Tocopherol quantification was performed using $\alpha$-tocopherol standard (Merck Co., Darmstadt, Germany).

\subsection{Phenolic compositions of the corn oils}

The phenolic compounds were analyzed with a RP-HPLC system coupled to a SPD-M20A diode array detector (Shimadzu Corporation, Kyoto, Japan) according to Moulehi et al., (2012) with minor modifications. The extraction of phenolic compounds from all oil samples was performed by Garcia-Villalba et al., (2010) and all methanolic extracts were filtered through a $0.45 \mu \mathrm{m}$ membrane filter before injection into the HPLC system. The separation was carried out on a Zorbax Eclipse Plus C18 column $(250 \mathrm{~mm} \times 4.6 \mathrm{~mm}$ ID $\times 5 \mu \mathrm{m}$, Agilent Technologies, USA) at $25{ }^{\circ} \mathrm{C}$. The mobile phase consisted of acetonitrile (solvent A) and water with $0.2 \%$ sulphuric acid (solvent B) and the flow rate was kept at $0.5 \mathrm{~mL} / \mathrm{min}$. The gradient program was as follows: $80 \% \mathrm{~A} / 20 \%$ B $0-18 \mathrm{~min}$, $70 \%$ A $/ 30 \%$ B 18-24 min, 60\% A/40\% B 24-30 min, $50 \%$ A $/ 50 \%$ B 30-36 min, 40\% A/60\% B 36-40 min, $45 \% \mathrm{~A} / 55 \%$ B $40-45 \mathrm{~min}, 35 \% \mathrm{~A} / 65 \%$ B $45-50 \mathrm{~min}$, $20 \% \mathrm{~A} / 80 \%$ B $50-52 \mathrm{~min}, 10 \% \mathrm{~A} / 90 \%$ B $52-54 \mathrm{~min}$, $100 \%$ B $54-70 \mathrm{~min}, 45 \%$ A $/ 55 \%$ B $70-72 \mathrm{~min}, 80 \%$ $\mathrm{A} / 20 \%$ B $72-74 \mathrm{~min}$. The injection volume was $20 \mu \mathrm{l}$, and obtained peaks were monitored at $280 \mathrm{~nm}$. Phenolic compounds were identified according to their retention times against those of commercially available standards.

\subsection{Thermal analyses of the corn oils}

Thermal parameters of the oil samples were determined with a Perkin-Elmer 4000 Series Differential Scanning Calorimeter (DSC) (Groningen, The Netherlands). The instrument was previously calibrated with Indium and Zinc standards and purged with nitrogen at $50 \mathrm{~mL} / \mathrm{min}$ flow rate. First, 5-7 mg oil sample were weighed and sealed hermetically in aluminium pans. Then the temperature program was applied by heating samples from room temperature to $110^{\circ} \mathrm{C}$ by 10 ${ }^{\circ} \mathrm{C} / \mathrm{min}$ rate, then cooling to $-70^{\circ} \mathrm{C}$ by $10{ }^{\circ} \mathrm{C} / \mathrm{min}$ rate and holding at that temperature for $3 \mathrm{~min}$, and finally heating again to $50{ }^{\circ} \mathrm{C}$ by $5{ }^{\circ} \mathrm{C} / \mathrm{min}$ rate.
Pyris 1 Manager Software was used to calculate the thermal parameters, melting temperature $\left(\mathrm{T}_{m}\right)$, melting enthalpy $\left(\Delta \mathrm{H}_{m}\right)$, crystallization temperature $\left(\mathrm{T}_{c}\right)$ and crystallization enthalpy $\left(\Delta \mathrm{H}_{c}\right)$ (Yllmaz et al., 2015c). Oxidative induction time (OIT) was also measured with the DSC by heating the sample from $30^{\circ} \mathrm{C}$ to $130{ }^{\circ} \mathrm{C}$ at $20^{\circ} \mathrm{C} / \mathrm{min}$ heating rate, while flushing nitrogen $(50 \mathrm{~mL} / \mathrm{min})$, and then by isothermal temperature programming at $130{ }^{\circ} \mathrm{C}$ with $50 \mathrm{~mL} / \mathrm{min}$ purified oxygen $(99.8 \%)$ application on the samples. The thermograms of the samples were calculated by using 1 Manager Software to calculate the OIT value (Yilmaz et al., 2015c).

\subsection{Determination of volatile compounds of the corn oils}

The volatile compounds in the corn oils were analyzed according to the technique of Krist et al., (2006) with minor modifications. Volatile compounds were collected from the oil samples with the headspace solid phase microextraction (SPME) (2 cm to $50 / 30 \mu \mathrm{m}$ DVB / Carboxen / PDMS, Supelco, Bellafonte) technique (Pawliszyn, 2012). First, $2 \mathrm{~g}$ oil sample were weighed into a 40 $\mathrm{mL}$ amber SPME vial (Supelco, Bellafonte, USA) and $1 \mathrm{~g} \mathrm{NaCl}$ and $10 \mu \mathrm{L}$ internal standards-IS $(0.1 \mu \mathrm{L}$ of 2 -methyl-3-heptanone and $6 \mu \mathrm{L}$ of 2 -methylvaleric acid dissolved in $1 \mathrm{~mL}$ methanol) were added. The closed vial was vortexed for $1 \mathrm{~min}$ and put in a water bath (GFL, Germany) at $40^{\circ} \mathrm{C}$ for $10 \mathrm{~min}$ to collect the volatiles in the headspace. Then, a SPME ( $2 \mathrm{~cm}$ to $50 / 30 \mu \mathrm{m}$ DVB / Carboxen / PDMS, Supelco, Bellafonte) needle was inserted into the vial and SPME fiber was exposed to a depth of $2 \mathrm{~cm}$ in the headspace for $10 \mathrm{~min}$ at $40^{\circ} \mathrm{C}$ in a water bath. Finally, the volatile compounds isolated on the fiber were injected into the $\mathrm{GC} /$ MS (Agilent 6890N/Agilent 5875C mass spectrometer, Agilent Technologies, Wilmington, DE, USA) equipped with a non polar HP5 MS column $(30 \mathrm{~m} \times 0.25 \mathrm{~mm}$ ID $\times 0.25 \mu \mathrm{m}, \mathrm{J} \& \mathrm{~W}$ Scientific, Folsom, CA). The GC conditions were described in a previous study (Yilmaz et al., 2015a). Identification of the volatiles was based on the comparison of the mass spectra of unknown compounds with those in the National Institute of Standards and Technology (NIST, 2008) and Wiley Registry of Mass Spectral Data, databases (McLafferty, 2005) and Retention (Kovats) index. Volatile compound quantification was based on the relative abundances calculated positively by the Equation given below.

$\begin{aligned} & \text { Mean relative } \\ & \text { abundance }(\mu \mathrm{g} / \mathrm{kg})\end{aligned}=\frac{\text { Concentration of IS } \times \text { Peak area of compound }}{\text { Peak area of the IS }}$ 


\subsection{Consumer test of the corn oils}

Sensory attributes (appearance, color, odor, taste/ flavor) of each oil sample were assessed by 110 individual panelists (61 females - 49 males aged 20-45 years) using a 5-point hedonic scale $(1=$ dislike extremely to $5=$ like extremely). All the oil samples were coded with three digit numbers and presented in clear glass cups with metal lids. Panelists first evaluated the appearance and color of each sample, and then tasted and swallowed it. Two samples of each treatment group were tested twice by each of the panelists at different sessions, randomly. The panelists were provided with warm water and unsalted crackers to cleanse the palate between sensory evaluations. All evaluations were at room temperature and under day light. The mean scores of the sensory attributes collected by the hedonic scales were calculated.

\subsection{Statistical analyses}

Cold pressing of the corn germs was duplicated and 2 batches of refined winterized corn oils were sampled to be the duplicate samples. For each of these duplicate samples, all analyses were performed in at least duplicate, if not triplicate. All values in the tables provided average of these determinations \pm standard error. Comparison of the measured properties for corn oil samples and statistically significant differences between groups were determined by oneway ANOVA and Tukey's tests. Sensory evaluation data was analyzed with non-parametric KruskalWallis and Dunn's test. Minitab ver. 16.1.1 (Minitab, 2010) and SPSS package (SPSS, 1994) programs were used for all statistical evaluations. There was a minimum $95 \%$ level of confidence for the statistics.

\section{RESULTS AND DISCUSSION}

\subsection{Physicochemical properties}

The measured physical properties of the cold pressed corn oils (CPCO) and refined winterized corn oils (RWCO) are presented in Table 1. The two oil samples can be visualized in Figure 1 as well. Most of the differences in appearance can easily be observed from Figure 1 and Table 1.

Although there is no significant difference between samples for refractive indices, statistically significant difference exists for the viscosity values. A significant difference exists between the two oil samples for the turbidity value. It is quite expected that refined winterized oils are truly clear since during the refining procedures all particles causing certain turbidities were removed. The cold pressed oil was only centrifuged to remove water and suspended materials, but some fine suspended materials and high molecular weight fractions still remain inside the oil. Supporting this assumption,

TABlE 1. Physico-chemical properties of the corn oils

\begin{tabular}{lcc}
\hline Property & Cold Pressed Corn Oil & Refined Winterized Corn Oil \\
\hline Refractive index $\left(25^{\circ} \mathrm{C}\right)$ & $1.47 \pm 0.01$ & $1.47 \pm 0.01$ \\
Viscosity $\left(25^{\circ} \mathrm{C}, \mathrm{cP}\right)$ & $56.85 \pm 0.05^{\mathrm{a}^{*}}$ & $55.60 \pm 0.10^{\mathrm{b}}$ \\
Turbidity $\left(25^{\circ} \mathrm{C}, \mathrm{NTU}\right)$ & $77.50 \pm 0.50^{\mathrm{a}}$ & $1.00 \pm 0.01^{\mathrm{b}}$ \\
Color L & $33.79 \pm 0.34^{\mathrm{b}}$ & $42.91 \pm 0.41^{\mathrm{a}}$ \\
$\mathrm{a}^{*}$ & $5.02 \pm 0.10^{\mathrm{a}}$ & $-2.52 \pm 0.09^{\mathrm{b}}$ \\
$\mathrm{b}^{*}$ & $9.91 \pm 0.03^{\mathrm{b}}$ & $17.61 \pm 0.75^{\mathrm{a}}$ \\
Sediment content $(\%)$ & $6.89 \pm 0.24^{\mathrm{a}}$ & $3.60 \pm 0.03^{\mathrm{b}}$ \\
Free fatty acidity (\% linoleic acid) & $1.16 \pm 0.06^{\mathrm{a}}$ & $0.23 \pm 0.02^{\mathrm{b}}$ \\
Acid value (mg KOH/g oil) & $2.32 \pm 0.12^{\mathrm{a}}$ & $0.42 \pm 0.01^{\mathrm{b}}$ \\
Peroxide value (meq O $/ \mathrm{kg}$ oil) & $9.29 \pm 0.03^{\mathrm{a}}$ & $6.67 \pm 1.53^{\mathrm{b}}$ \\
p-Anisidine value & $9.09 \pm 0.17^{\mathrm{a}}$ & $6.48 \pm 0.72^{\mathrm{b}}$ \\
Iodine number $(\mathrm{g} \mathrm{I} / 100 \mathrm{~g}$ oil) & $98.30 \pm 15.60$ & $105.83 \pm 3.33$ \\
Saponification number (mg KOH/g oil) & $205.43 \pm 1.35^{\mathrm{a}}$ & $194.13 \pm 1.00^{\mathrm{b}}$ \\
Unsaponifiable matter (\%) & $1.44 \pm 0.05^{\mathrm{a}}$ & $1.13 \pm 0.01^{\mathrm{b}}$ \\
Total phenolics (mg GA/kg oil) & $53.58 \pm 1.04^{\mathrm{a}}$ & $16.23 \pm 0.31^{\mathrm{b}}$ \\
Antioxidant capacity (mmol Trolox/kg oil) & $127.73 \pm 3.04$ & $\mathrm{ND}$ \\
Total carotenoid (mg/kg oil) & $7.41 \pm 0.36^{\mathrm{a}}$ & $0.14 \pm 0.01^{\mathrm{b}}$ \\
Zeaxanthin (mg/kg oil) & $7.89 \pm 0.38^{\mathrm{a}}$ & $0.15 \pm 0.01^{\mathrm{b}}$ \\
Total chlorophyll (mg pheophytin a/kg oil) & $\mathrm{ND}$ & $\mathrm{ND}$ \\
\hline
\end{tabular}

${ }^{*_{\mathrm{a}-\mathrm{b}}}$ means in the same horizontal rows followed by different superscript letters were significantly different $(p<0.05)$. ND, not detected 


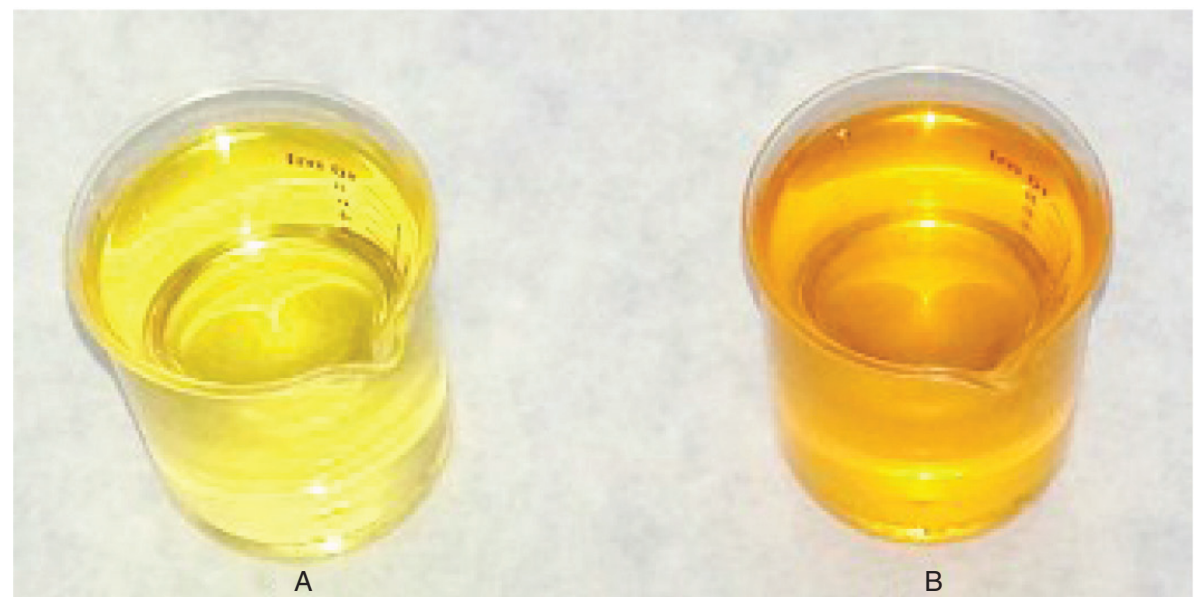

FIGURE 1. The corn oils produced by refining winterization process (A) and cold pressing technique (B).

the sediment content of CPCO was much higher than RWCO, indicating some possible reasons for high turbidity. Statistically significant differences also exist for the color parameters (Table 1). The L value (0-black/100-white) or luminosity of RWCO is much higher, indicating a correlation with the low turbidity measured. The $\mathrm{a}^{*}$ value (+red/-green) indicates that the CPCO is more reddish than the other sample. Actually RWCO is rather greenish in color as shown by the $\mathrm{a}^{*}$ value. The other color parameter, $b^{*}$ value (+yellow/-blue) showed that RWCO is more yellow than the CPCO sample (Table 1 and Figure 1). Strecker et al., (1996) suggested 1.4753 as a refractive index, and 30.80 and $18.15 \mathrm{cP}$ as viscosities at 40 and $60{ }^{\circ} \mathrm{C}$ for corn oils. Generally, our results concur with these values.

The main chemical characteristics of the corn oil samples are also summarized in Table 1. Free fatty acidity (FFA) of CPCO was $1.16 \%$, and higher than that of the RWCO $(0.23 \%)$, but this can be considered quite low compared to other cold pressed oils (Y1lmaz et al., 2015a; Y1lmaz et al., 2015b). The measured acid values are in accordance with the FFA values as well. According to the codex standard for vegetable oils (Codex Stan, 2015), the upper limit of acid value is $4.0 \mathrm{mg} \mathrm{KOH} / \mathrm{g}$ oil. Hence, the CPCO is quite acceptable in terms of acidity. The peroxide value $(\mathrm{PV})$ of $\mathrm{CPCO}\left(9.29 \mathrm{meq} \mathrm{O}_{2} / \mathrm{kg}\right)$ was significantly higher than that of the RWCO (6.67 meq $\mathrm{O}_{2} / \mathrm{kg}$ ). According to the Codex Standard for Named Vegetable Oils (Codex Stan, 2015), the PV must be lower than $15 \mathrm{meq} \mathrm{O}_{2} / \mathrm{kg}$ for cold pressed oils, and CPCO can be acceptable by this limit as well. Similarly, $p$-anisidine ( $p$-AV) values agree with the PVs measured. The oxidation level of oil heavily depends on its production, processing, and storage conditions; hence, only acceptable upper limits could be meaningful for suitability of consumption. Each oil might have different oxidation stability, depending on its chemical composition, purity, and storage conditions (O'Brien, 2004). The $\mathrm{PV}$ and $p$-AV reported in this study indicate that CPCO does not pose any immediate health hazard based on oil oxidation, and is consumable as it is pressed. The iodine numbers indicate significant difference between the two samples (Table 1). This is also expected, since in the RWCO sample, the waxes and higher melting point triglyceride fractions must have been removed by the winterization process, whereas those higher melting components are likely to remain in the CPCO sample after pressing and centrifugation. In the literature, iodine values for corn oils are given between 118 and 133 (Strecker et al., 1996; O'Brien, 2004). The sediment content, color parameters and turbidity values have indicated that an adsorbent treatment and/or full industrial filtration of CPCO after pressing may significantly improve these properties. The saponification number of $\mathrm{CPCO}$ was higher than that of the RWCO (Table 1). Both Strecker et al., (1996) and O'Brien, (2004) reported saponification numbers of corn oils to be 187 to 193 . The number measured in the CPCO (205.43 mg KOH/g oil) sample is higher than those reported in the literature, which may be due to the high molecular weight component present in the unrefined cold pressed oil. The unsaponifiable matter content of the samples was 1.44 and $1.13 \%$ for the CPCO and RWCO, respectively. The unsaponifiable number for corn oils is given from 1.3 to $2.3 \%$ (O'Brien, 2004). Hence, there is an agreement between our findings and the literature data.

Some other chemical properties related to the nutritional value of the oils were also reported (Table 1). Total phenolic content, antioxidant capacity, total carotenoid and zeaxanthin contents of the CPCO sample were significantly higher than those measured in the RWCO sample. For both samples, there are no quantifiable levels of chlorophyll. 
These results clearly prove that most phenolics and pigments are lost during the refining processes. These compounds constitute antioxidant capacity, and in fact no measured antioxidant capacity was observed in the RWCO sample. This suggests an important nutritional loss as well. In one study (Daugan et al., 2011), the $\beta$-carotene content of commercial corn oil was reported as $0.91 \mathrm{ppm}$. Another study (Rafalowski et al., 2008) reported the $\beta$-carotene content of cold pressed corn oil as $3.56 \mathrm{mg} / 100 \mathrm{~g}$ oil, and indicated its absence in the refined oil. Tuberoso et al., (2007) reported the chlorophylls content as $4.9 \mathrm{mg} / \mathrm{kg}$, $\beta$-carotene content as $0.9 \mathrm{mg} / \mathrm{kg}$, and TEAC activity to be $2.30 \mathrm{mmol} / \mathrm{L}$ for corn oil. The total phenolic content as caffeic acid equivalent for corn oil was reported as $1.26 \mathrm{mg}$ CAE/100 g oil, and DPPH radical scavenging activity and EC50 values were reported as $11.1 \%$ and $14.8 \mu \mathrm{g}$, respectively (Siger et al., 2008). Our results and literature usually concur, but some differences exist depending on the material source and differences in analytical methods.

\subsection{Fatty acid, sterol and $\alpha$-tocopherol compositions}

Five fatty acids were quantified in the corn oil samples (Table 2). The fatty acid composition of the CPCO and RWCO samples were very similar. Both included around 53\% linoleic and 30\% oleic acid as the major fatty acids.

In general, the fatty acid compositions of our samples concur with the literature (Strecker et al., 1996; O’Brien, 2004; Codex Stan, 2015; Rafalowski et al., 2008). There were statistically significant differences between the two samples for the sterol composition (Table 2). 24-Methylene cholesterol, campesterol, $\Delta$-7-campesterol, $\Delta$-5,23-stigmasterol, cholesterol and $\Delta$-5,24-stigmasterol were absent in the RWCO, while quantified in small amounts in the CPCO sample. Among the fifteen different sterols, the majority was composed of $\beta$-sitosterol (60-62\%), campesterol (19-22\%), stigmasterol (6-7\%) and sitosterol $(2-4 \%)$. These findings are in agreement with those ranges given in the standard for vegetable oils (Codex Stan, 2015). Strecker et al., (1996)

TABLE 2. The fatty acid, sterol and $\alpha$-tocopherol compositions of the corn oils

\begin{tabular}{|c|c|c|}
\hline Component & Cold Pressed Corn Oil & Refined Winterized Corn Oil \\
\hline \multicolumn{3}{|l|}{ Fatty acids (\%) } \\
\hline Palmitic (C16:0) & $11.81 \pm 0.04$ & $11.11 \pm 0.01$ \\
\hline Palmitoleic (C16:1) & ND & ND \\
\hline Stearic $(\mathrm{C} 18: 0)$ & $2.07 \pm 0.01$ & $2.16 \pm 0.04$ \\
\hline Oleic (C18:1 n-9) & $29.90 \pm 0.03^{b}$ & $30.81 \pm 0.01^{\mathrm{a}^{*}}$ \\
\hline Linoleic (C18:2 n-6) & $53.89 \pm 0.01^{\mathrm{a}}$ & $52.93 \pm 0.01^{\mathrm{b}}$ \\
\hline Linolenic (C18:3 n-3) & $1.11 \pm 0.02^{\mathrm{a}}$ & $0.82 \pm 0.01^{\mathrm{b}}$ \\
\hline \multicolumn{3}{|l|}{ Sterols $(\%)$} \\
\hline Cholesterol & $0.52 \pm 0.17$ & $0.51 \pm 0.09$ \\
\hline Brassicasterol & $0.14 \pm 0.03$ & $0.15 \pm 0.05$ \\
\hline 24-Methylen cholesterol & $1.01 \pm 0.12$ & ND \\
\hline Campesterol & $19.61 \pm 0.16^{b}$ & $21.90 \pm 0.21^{\mathrm{a}}$ \\
\hline Campestanol & $1.83 \pm 0.03$ & ND \\
\hline Stigmasterol & $6.44 \pm 0.82$ & $6.77 \pm 0.55$ \\
\hline$\Delta$-7-Campesterol & $0.38 \pm 0.02$ & ND \\
\hline$\Delta$-5,23-Stigmastadienol & $0.26 \pm 0.06$ & ND \\
\hline Chlerosterol & $0.57 \pm 0.05$ & ND \\
\hline$\beta$-sitosterol & $60.75 \pm 0.26$ & $62.23 \pm 0.42$ \\
\hline Sitostanol & $4.20 \pm 0.09$ & $2.66 \pm 0.65$ \\
\hline$\Delta-5$-Avenasterol & $3.02 \pm 0.15$ & $3.55 \pm 0.02$ \\
\hline$\Delta-5,24-$ Stigmastadienol & $0.18 \pm 0.01$ & ND \\
\hline$\Delta$-7-Stigmastenol & $0.56 \pm 0.22$ & $1.18 \pm 0.07$ \\
\hline$\Delta$-7-Avenasterol & $0.52 \pm 0.13$ & $0.92 \pm 0.01$ \\
\hline \multicolumn{3}{|l|}{ Tocopherol (mg/kg oil) } \\
\hline$\alpha$-Tocopherol & $248.83 \pm 0.62^{\mathrm{a}}$ & $159.60 \pm 3.99^{b}$ \\
\hline
\end{tabular}

\footnotetext{
${ }^{* a-b}$ means in the same horizontal rows followed by different superscript letters were significantly different $(p<0.05)$.
} $\mathrm{ND}$, not detected 
indicated $\beta$-sitosterol, campesterol and stigmasterol as the major sterols of corn oils. The only tocopherol quantified in these samples was $\alpha$-tocopherol (Table 2). Amount of $\alpha$-tocopherol in the CPCO $(248.83 \mathrm{mg} / \mathrm{kg})$ was significantly higher than that found in the RWCO (159.60 mg/kg) sample. Clearly during refining, significant losses of $\alpha$-tocopherol have occurred. Rafalowski et al., (2008) have determined the tocopherol composition of both refined and cold pressed corn oil among ten other oils. They have quantified $27.22,91.76$, and $5.93 \mathrm{mg} / 100 \mathrm{~g}$ oil of $\alpha$-tocopherol, $\gamma$-tocopherol and $\delta$-tocopherol in the cold pressed sample, while the same tocopherols were quantified in refined oils as 26.11, 44.31, and $0.0 \mathrm{mg} / 100 \mathrm{~g}$ oil, respectively. Our study concurs in this finding that during refining most tocopherols are lost. Strecker et al., (1996) has given the tocopherol composition of corn oil as $19.1,94.2$, and 4.2 $\mathrm{mg} / 100 \mathrm{~g}$ for the $\alpha-, \gamma$ - and $\delta$-tocopherols. Clearly, we measured only $\alpha$-tocopherol, and our finding is in agreement with the literature.

\subsection{Phenolic compositions}

Some flavonoids and phenolic acids were measured and reported in Table 3 for the CPCO sample.

No phenolics were quantified in the refined corn oil samples. It can be said that during refining, all phenolics were degraded or lost for the refined corn oil. Among the analyzed 8 flavonoids, only hesperidin $(23.81 \mathrm{mg} / \mathrm{kg})$, and rutin $(14.17 \mathrm{mg} /$ $\mathrm{kg}$ ) were quantified. Except for $o$-coumaric acid, gallic, syringic, trans-ferulic and rosmaniric acids were quantified as the phenolic acids (Table 3). In one study (Pandey et al., 2013), different maize samples (baby corn, raw, boiled, baked, fried, ripe corns, popcorn, stylar) were analyzed for phenolic

TABLE 3. The phenolic composition of the cold pressed corn oil

\begin{tabular}{lc}
\hline Phenolics & Amount $(\mathbf{m g} / \mathbf{k g})$ \\
\hline Catechin & ND \\
Eriocitrin & ND \\
Rutin & $14.17 \pm 0.28$ \\
Naringin & ND \\
Naringenin & ND \\
Hesperidin & $23.81 \pm 0.02$ \\
Neohesperidin & ND \\
Kaempherol & ND \\
Phenolic acids & \\
Gallic acid & $16.18 \pm 0.36$ \\
Syringic acid & $6.91 \pm 0.04$ \\
trans-Ferulic acid & $1.94 \pm 0.07$ \\
Rosmaniric acid & $2.86 \pm 0.01$ \\
$o$-Coumaric acid & ND \\
\hline
\end{tabular}

ND, not detected acid composition. Raw maize contained 4.6, 3.2, 0.99 and $0.57 \mu \mathrm{g} / \mathrm{g}$ fresh weight of gallic, caffeic, ferulic and salicylic acids, respectively. Another study (Tuberoso et al., 2007) reported the phenolic compositions of nine different oils including maize oil. In maize oil, $2.8 \mathrm{ppm}$ vanillin, $0.5 \mathrm{ppm}$ ferulic acid, and 0.9 ppm trans-cinnamic acid were quantified. Siger et al., (2008) have measured the phenolic acid content of cold pressed corn oil. They have quantified $1.7,1.9,5.8$, and $0.6 \mu \mathrm{g} / 100 \mathrm{~g}$ oil of p-hydroxybenzoic, $p$-coumaric, ferulic, and sinapic acids, respectively. All these literature data indicate that cold pressed corn oils include some important phenolic compounds, and these molecules are bioactive components for some health benefits, including antioxidant, anti-bacterial, anti-inflammatory, anti-allergic, anti-thrombotic, anti-carcinogenic activities, hepatoprotective and vasodilatory actions (Pandey et al., 2013).

\subsection{Thermal properties}

Crystallization and melting temperatures and enthalpies of the two corn oil samples are reported in Table 4. Since a thermal cycling procedure was applied during the thermal analysis, it was possible to observe the whole behavior of the corn oils during heating (up to $50{ }^{\circ} \mathrm{C}$ ) and cooling (up to $-70^{\circ} \mathrm{C}$ ) stages.

There were some statistically significant differences between the samples. Crystallization onset and peak temperatures were lower for the cold pressed sample than the refined-winterized sample. Likewise, melting peak temperature and enthalpy were lower for the cold pressed sample. These differences are expected, and might be caused by the waxes and/or high melting fractions present in the CPCO sample. Those fractions were removed as expected from the RWCO sample by the winterization process applied previously. It was stated that fats and oils exhibit a range of crystallization and melting temperatures, rather than definite points since they are heterogeneous mixtures of different triglycerides. In addition, a shift between crystallization and melting onset temperatures are acknowledged as a common phenomenon for unsaturated oils (Co and Marangoni, 2012). We have not found thermal data for corn oils in the literature, and this study may provide this information for interested researchers.

The oxidation induction times (OIT) of the samples determined by DSC are also presented in Table 4. Clearly, the cold pressed sample was significantly more stable against oxidation due to its prolonged induction time $(65.74 \mathrm{~min})$. Since cold pressed oils retain most of their minor components including phenolics and tocopherols compared to refined oils, they might have higher oxidation stability. This was also the case for these samples as 
evidenced from the measured total phenolic contents and antioxidant activity (Table 1) and phenolic compositions (Table 3).

\subsection{Volatile aromatics compositions}

The volatile aromatic compounds determined in the CPCO and RWCO samples are presented in Table 5. There are 22 volatiles detected in the cold pressed, and 7 volatiles and hexane detected in the refined sample. Clearly, most volatiles are lost in the refined sample, possibly during the alkali refining and deodorization processes.

The most abundant volatiles present in the CPCO sample were hexanal, acetic acid, 3-methylbutanal, hexanoic acid and butanoic acid while only minor amounts of hexanal, heptanal, hexanoic acid, limonene, 2-ethyl hexanol, 3-carene, and nonanal remained in the RWCO sample. It is well known that in any food product, the characteristic aroma is provided by the volatiles present all together, but not in an order of higher concentrations, rather

TABLE 4. Thermal properties of the corn oils

\begin{tabular}{|c|c|c|c|c|c|c|c|}
\hline Sample & $\begin{array}{l}\text { Onset }_{c} \\
\left({ }^{\circ} \mathbf{C}\right)\end{array}$ & $\begin{array}{c}\text { Crystallization } \\
\mathbf{T}_{\mathrm{c}}\left({ }^{\circ} \mathrm{C}\right)\end{array}$ & $\begin{array}{l}\Delta \mathbf{H}_{\mathrm{c}} \\
(\mathrm{J} / \mathrm{g})\end{array}$ & $\begin{array}{c}\text { Onset }_{\mathrm{m}} \\
\left({ }^{\circ} \mathrm{C}\right)\end{array}$ & $\begin{array}{l}\text { Melting } \\
\mathrm{T}_{\mathrm{m}}\left({ }^{\circ} \mathrm{C}\right)\end{array}$ & $\begin{array}{l}\Delta \mathbf{H}_{\mathrm{m}} \\
(\mathrm{J} / \mathrm{g})\end{array}$ & $\begin{array}{c}\text { Oxidative } \\
\text { induction time } \\
\text { (min) }\end{array}$ \\
\hline $\begin{array}{l}\text { Cold Pressed } \\
\text { Corn Oil }\end{array}$ & $-10.52 \pm 0.03^{b}$ & $-11.82 \pm 0.02^{b}$ & $-2.91 \pm 0.01^{\mathrm{a}}$ & $-25.66 \pm 0.22^{a}$ & $-15.10 \pm 0.01^{\mathrm{ab}}$ & $6.27 \pm 0.02^{\mathrm{b}}$ & $65.74 \pm 0.34^{\mathrm{a}}$ \\
\hline $\begin{array}{l}\text { Refined Winterized } \\
\text { Corn Oil }\end{array}$ & $-13.14 \pm 0.06^{\mathrm{a}}$ & $-15.48 \pm 0.04^{\mathrm{a}}$ & $-2.26 \pm 0.04^{a}$ & $-25.88 \pm 0.04^{\mathrm{a}}$ & $-16.52 \pm 0.03^{\mathrm{a}}$ & $8.12 \pm 0.02^{\mathrm{a}}$ & $27.70 \pm 0.29^{b}$ \\
\hline
\end{tabular}

TABLE 5. Volatiles compositions of the corn oils

\begin{tabular}{|c|c|c|c|c|c|}
\hline \multirow[b]{2}{*}{ No } & \multirow[b]{2}{*}{ RI* } & \multirow[b]{2}{*}{ Volatile compounds } & \multirow[b]{2}{*}{ Aroma / Flavor Description ${ }^{Y}$} & \multicolumn{2}{|c|}{ Concentration $(\mu \mathrm{g} / \mathrm{kg}$ oil $)$} \\
\hline & & & & Cold Pressed & Refined Winterized \\
\hline 1 & 600 & Hexane & - & ND & $22.93 \pm 4.22$ \\
\hline 2 & 603 & Acetic acid & Pungent, sour vinegar & $26.16 \pm 19.65$ & ND \\
\hline 3 & 641 & 3-Methyl-butanal & Almond, nutty, buttery & $12.52 \pm 0.68$ & ND \\
\hline 4 & 727 & 1-Pentanol & Green, wax & $1.51 \pm 0.12$ & ND \\
\hline 5 & 752 & Butanoic acid & Rancid, buttery, acidic, cheesy & $4.13 \pm 3.05$ & ND \\
\hline 6 & 765 & Hexanal & Fresh, green, grass & $31.04 \pm 1.23$ & $0.71 \pm 0.18$ \\
\hline 7 & 838 & 2,3-Methyl butanoic acid & Rancid, sweaty odor, cheesy & $1.47 \pm 0.59$ & ND \\
\hline 8 & 848 & 2-Furanmethanol & Oily, burnt sugar & $1.11 \pm 0.09$ & ND \\
\hline 9 & 896 & 2-Heptanone & Spicy, fruity, coconut & $0.44 \pm 0.01$ & ND \\
\hline 10 & 914 & Heptanal & Fresh, oily, green & $0.67 \pm 0.02$ & $0.02 \pm 0.03$ \\
\hline 11 & 973 & $\alpha$-Pinene & Pine, turpentine, woody & $0.06 \pm 0.01$ & ND \\
\hline 12 & 1020 & Benzaldehyde & Bitter, almond & $0.23 \pm 0.02$ & ND \\
\hline 13 & 1087 & 1-Octen-3-ol & Mushroom, earthy, green, oily & $0.91 \pm 0.13$ & ND \\
\hline 14 & 1112 & 2-Pentyl furan & Beany, grassy, licorice & $2.33 \pm 0.71$ & ND \\
\hline 15 & 1184 & Hexanoic acid & Sour, fatty, sweat, cheese & $4.47 \pm 3.41$ & $0.14 \pm 0.03$ \\
\hline 16 & 1210 & Limonene & Citrus, sweet, terpenic & $0.31 \pm 0.04$ & $0.34 \pm 0.01$ \\
\hline 17 & 1237 & 2-Ethyl hexanol & Earthy, slightly floral & $0.12 \pm 0.01$ & $0.03 \pm 0.0423$ \\
\hline 18 & 1254 & 3-Octen-2-one & Earthy, spicy, herbal, mushroom & $0.56 \pm 0.04$ & ND \\
\hline 19 & 1315 & 3-Carene & Sweet, citrus & ND & $0.01 \pm 0.01$ \\
\hline 20 & 1316 & (E)-2-Octenal & Fresh, cucumber, fatty, green, herbal & $0.05 \pm 0.01$ & ND \\
\hline 21 & 1455 & (E,E)-3,5-Octadien-2-one & Fruity, green, grassy & $0.04 \pm 0.01$ & ND \\
\hline 22 & 1514 & Nonanal & Citrus, rose, cucumber & $0.19 \pm 0.01$ & $0.03 \pm 0.01$ \\
\hline 23 & 1771 & 3-Methyl heptyl acetate & Sweet, banana, fruity, ripe & $0.02 \pm 0.01$ & ND \\
\hline
\end{tabular}

${ }^{*} \mathrm{RI}$ (Kovat Index) on HP 5 MS column

${ }^{\sharp}$ Aromatic definitions of the volatile compounds are found from the web pages of http://www.thegoodscentscompany.com/index.html\# and http://www.flavornet.org/flavornet.html.

$\mathrm{ND}$, not detected 
in the order of aroma threshold value. The aroma threshold value is defined as the minimum concentration of any aromatic volatile which can be perceived by humans. It is well known that the aroma threshold of some volatiles is much lower, and they can contribute much more to the perceived aroma at their very low concentrations than the other volatiles present in the same food at very high amounts (Meilgaard et al., 1991). The green, fresh, herbal, and sour attributes are the most frequent descriptors for the measured aromatic volatiles in the samples (Table 5). There is a fairly limited number of studies about volatile compounds of corn oils. In one study (Tuan, 2011), 29 volatile compounds were identified in the corn oils. There were some similarities between this and that study, and octane, 2,6-dimethyl-3-heptanone, 2-heptenal, 2-pentylfuran, nonanal, hexedecanoic acid, 9-octadecenoic acid ethyl ester were determined as the same or very similar compounds. The other volatiles were usually different isomers of the same base compounds, but acetic acid, $\alpha$-pinene, benzaldehyde, limonene, and 3 -carene were identified only in our study. These volatiles distinctly provide almond, citrus, pine, buttery and terpenic aroma notes. It is quite possible that cold pressing of the corn germ yielded the advantage of the presence of these various volatiles for the oil. Solid Phase Microextraction (SPME) with different resins was studied to identify the volatiles in corn and soybean oils (Steenson et al., 2002). In corn oil, 13 different volatiles were identified with 2-heptenal, trans-2-octenal, pentane and 2,4-heptedienal as the most abundant ones. These and others listed are similar to those determined in this study (Table 5). In another study (Goicoechea and Guillén, 2014), the volatile compounds generated in corn oils during storage at room temperature for various times (12-103 months) were measured. Usually oxidized samples included many secondary oxidation compounds including alkanals, 2-alkenals, 2,4-alkadienals, acids, alcohols, ketones, alkylfurans, lactones and $\alpha, \beta$-unsaturated aldehydes. As storage time extended, the kinds and amounts of volatiles were enhanced. Even in this study, at earlier storage times, some similarities between the detected volatiles (hexanoic and butanoic acid, hexenal, nonanal, limonene, and some furans etc.) of our samples were observed.

The presence of hexane $(22.93 \mu \mathrm{g} / \mathrm{kg}$ oil $)$ in the RWCO sample is an important issue to address here. Since it is absent in the CPCO sample, it can easily be argued that hexane is originated from the solvent extraction process applied previously to the RWCO sample. The commercial hexane used in oil extraction is a mixture of low molecular weight linear, branched and cyclic saturated alkanes. It is acknowledged that hexane is a toxic substance, and acute inhalation of humans to high doses creates dizziness, giddiness, slight nausea, and headache; chronic exposure is characterized with polyneuropathy in humans, with numbness in the extremities, muscular weakness, blurred vision, headache, and fatigue (TGK, 2002; Mirghani and Che Man, 2003). It is stated in the Turkish codex standard for the determination of the maximum limits of definite contaminants in foods (TGK, 2002) that the maximum residual limit of hexane in fats/oils is 5 $\mathrm{mg} / \mathrm{kg}$, whereas the United States Environmental Protection Agency has published some health data for hexane but it was incomplete (Mirghani and Che Man, 2003). It was also stated that hexane residues in refined foods would be less than $2 \mathrm{ppm}$, since if 80 $\mathrm{g}$ fat per day is consumed by a $70 \mathrm{~kg}$ weight person, such a residual level would be equivalent to 2.29 $\mu \mathrm{g} / \mathrm{kg} / \mathrm{day}$, which is a toxicologically effective level (Hautfenne et al., 1987). Although the residual hexane level in the RWCO sample is much lower than the permitted maximum level, CPCO still provides one of the major advantages of being free of any solvents or chemicals.

\subsection{Consumer acceptance}

Hedonic scores of appearance, color, odor and taste/flavor for the two corn oil samples with 110 volunteer consumers are shown in Figure 2.

All sensory scores for the CPCO sample were significantly lower than the RWCO sample. Except for the taste/flavor score of the CPCO sample, all attribute scores for both samples were higher than the neutrality point of 3.0 (neither like nor dislike); hence, it could be claimed that consumers accepted both samples. Improvements especially in the taste/ flavor and odor of the CPCO sample were determined as the main requirements based on the consumer test. A simple adsorption and/or combined adsorption/winterization process would improve sensory characteristics as well as turbidity and sediment values of the CPCO sample. This process may not cause significant losses in bioactive compounds. A deodorization process might greatly improve the odor characters of $\mathrm{CPCO}$, but deodorization usually causes heavy nutrient losses (O'Brien, 2004)

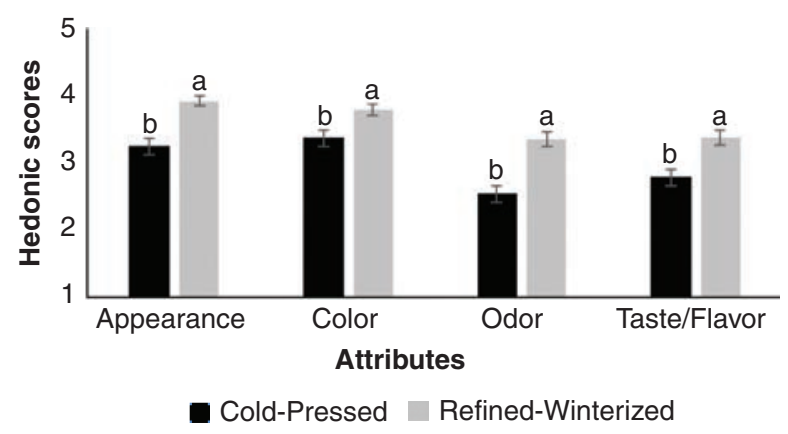

FIGURE 2. The consumer hedonic scores of the corn oils $(1=$ dislike extremely, $5=$ like extremely; $n=110)$. 
and we would not suggest it for cold pressed oils. Similar consumer responses to cold pressed capia pepper seed oil (Yilmaz et al., 2015a) and tomato seed oil (Yilmaz et al., 2015b) were observed in our laboratory.

\section{CONCLUSIONS}

This study proved that good quality cold pressed corn oils can be produced from clean and dry corn germ materials. As prerequisite for all seeds and kernels for cold pressing, corn germs must also be clean, pure, homogeneous, uncontaminated and with a suitable level of moisture for successful cold pressing. Most physical and chemical properties of cold pressed and fully refined corn oils were very similar, but some important differences exist for color, turbidity, and nutritionally important components like sterols, $\alpha$-tocopherol, and phenolic compounds. Generally, important losses in bioactive nutrients in the RWCO sample were documented in this study. As expected, volatile aromatic composition data suggests that most volatiles are lost in the refined sample. Furthermore, some residual hexane was found in the refined oil, which shows one of the advantages of cold pressing. In contrast, sensory scores for the CPCO sample were lower than those of the RWCO sample. In conclusion, mycotoxin and pesticide free, clean, pure and dry corn germs could be cold pressed to get oils rich in the bioactive compounds and special aromas. A comprehensive oil production system could be envisioned for a more health beneficial, chemical contaminant free and sensorially superior edible oil supply.

\section{ACKNOWLEDGMENTS}

This manuscript does not contain experiments using animals or human studies. The authors thank Cargill-Bursa for the provided materials for this study.

\section{REFERENCES}

Anonymous. 2015a. http://www.worldofcorn.com/\#world-cornproduction. Accessed 26 Jun 2016.

Anonymous. 2015b. http://www.hububatbirlik.org/TR,55/ statistikler.html. Accessed 10 Dec 2015

AOCS Methods Cc 10c-95, Ca 5a-40, Cd 3d-63, Cd 8-53, Cd 1-25, Cd 18-90, Tl 1a-64. 1997. Official methods and recommended practices of the American oil chemists' society, 5 th ed. AOCS Press, Champaign

Aydeniz B, Güneşer O, Y1lmaz E. 2014. Physico-chemical, sensory and aromatic properties of cold press produced safflower oil. J. Am. Oil Chem. Soc. 91, 99-110. http://dx.doi. org/10.1007/s11746-013-2355-4

Aydeniz B, Yilmaz E. 2012. Enrichment of frying oils with plant phenolic extracts to extend the usage life. Eur. J. Lipid Sci. Technol. 14, 933-941. http://dx.doi.org/10.1002/ ejlt.201100228
Co ED, Marangoni AG. 2012. Organogels: An alternative edible oil-structuring method. J. Am. Oil Chem. Soc. 89, 749-780. http://dx.doi.org/10.1007/s11746-012-2049-3

Codex Stan 210-1999 Rev. 2015. 2015. Codex Standard for Named Vegetable Oils. 1-13. http://www.fao.org/input/.../ standards/336/CXS 210e 2015.pdf. Accessed 23 Jan 2017

Dauqan E, Sani HA, Abdullah A, Muhamad H, Top AG. 2011. Vitamin $\mathrm{E}$ and beta carotene composition in four different vegetable oils. Am. J. App. Sci. 8, 407-412. http://dx.doi. org/10.3844/ajassp.2011.407.412

Dündar Emir D, Aydeniz B, Yllmaz E. 2015. Effects of roasting and enzyme pretreatments on yield and quality of cold pressed poppy seed oils. Turk. J. Agric. For. 39, 260-271. http://dx.doi.org/10.3906/tar-1409-34

Franke S, Fröhlich K, Werner S, Böhm V, Schöne F. 2010. Analysis of carotenoids and vitamin $\mathrm{E}$ in selected oilseeds, press cakes and oils. Eur. J. Lipid Sci. Technol. 112, 11221129. http://dx.doi.org/10.1002/ejlt.200900251

Garcia-Villalba R, Carrasco-Pancorbo A, Zurek G, Behrens M, Bassmann C, Segura-Carretero A, Fernandez-Gutierrez A. 2010. Nano and rapid resolution liquid chromatography-electrospray ionization-time of flight mass spectrometry to identify and quantify phenolic compounds in olive oil. J. Sep. Sci. 33, 2069-2078. http://dx.doi.org/10.1002/ jssc. 201000184

Goicoechea E, Guillén MD. 2014. Volatile compounds generated in corn oil stored at room temperature. Presence of toxic compounds. Eur. J. Lipid Sci. Technol. 116, 395-406. http://dx.doi.org/10.1002/ejlt.201300244

Grilo Câmara E, Costa PN, Gurgel CSS, Beserra AFM, Almeida FNS, Dimenstein R. 2014. Alpha-tocopherol and gamma-tocopherol concentration in vegetable oils. Food Sci. Technol. (Campinas). 34, 379-385. http://dx.doi. org/10.1590/S0101-20612014005000031

Hautfenne A, Pocklington WD, Wolff JP. 1987. Determination of hexane residues in oils - results of a collaborative study and the standardized method. Pure Appl. Chem. 59, 15611570. http://dx.doi.org/10.1351/pac198759111561

ISO Method 12228. 1999. Animal and vegetable fats and oilsdetermination of individual and total sterols contents, gas chromatographic method. International Organisation for Standardisation. Geneva, Switzerland

ISO Method 3596. 2000. Animal and vegetable fats and oils determination of unsaponifiable matter - method using diethyl ether extraction. International Organisation for Standardisation. Geneva, Switzerland

Khoddami A, Che Man YB, Roberts TH. 2014. Physicochemical properties and fatty acid profile of seed oils from pomegranate (Punica granatum L.) extracted by cold pressing. Eur. J. Lipid Sci. Technol. 116, 553-562. http://dx.doi. org/10.1002/ejlt.201300416

Krist S, Stuebiger G, Bail S, Unterweger H. 2006. Detection of adulteration of poppy seed oil with sunflower oil based on volatiles and triacylglycerol composition. J. Agric. Food Chem. 54, 6385-6389. http://dx.doi.org/10.1021/jf060500x

McLafferty FW. 2005. In Fred W. McLafferty (Ed.). Wiley Registry of Mass Spectral Data, 7th ed. John Wiley \& Sons Ltd, New York. ISBN: 978-0471473251, CD-ROM.

Meilgaard M, Civille GV, Carr BT. 1991. Sensory Evaluation Techniques. CRC Press, Boca Raton (Florida). ISBN 10: 0849342805 / ISBN 13: 9780849342806

Minitab. 2010. Minitab statistical software (Version 16.1.1). Minitab Inc State College, Pennsylvania, USA

Mirghani MES, Che Man YB. 2003. Determination of hexane residues in vegetable oils with FTIR spectroscopy. $J$. Am. Oil Chem. Soc. 80, 619-623. http://dx.doi.org/10.1007/ s11746-003-0748-3

Moulehi İ, Bourgou S, Ourghemmi İ, Tounsi MS. 2012. Variety and ripening impact on phenolic composition and antioxidant activity of mandarin (Citrus reticulate Blanco) and bitter orange (Citrus aurantium L.) seeds extracts. Ind. Crop. Prod. 39, 74-80. http://dx.doi.org/10.1016/j. indcrop.2012.02.013

NIST. 2008. NIST/EPA/NIH Mass Spectral Library. National Institute of Standards and Technology Standard Reference Data Program, MD 20899, Gaithersburg 
O'Brien RD. 2004. Fats and Oils: Formulating and Processing For Applications. CRC Press, New York. ISBN 9780203483664

Pandey R, Singh A, Maurya S, Singh UP, Singh M. 2013. Phenolic acids in different preparations of maize (Zea mays) and their role in human health. Int. J. Curr. Microbiol. App. Sci. 2, 84-92. ISSN: 2319-7706

Pawliszyn J. 2012. Theory of Solid-Phase Microextraction, in Pawliszyn J (Ed.). Hanbook of Solid Phase Microextraction. Elsevier Inc, Waltham, USA, 13-57. http://dx.doi. org/10.1016/B978-0-12-416017-0.00002-4

Rafalowski R, Zegarska Z, Kuncewicz A, Borejszo Z. 2008. Fatty acid composition, tocopherol and B-carotene content in Polish commercial vegetable oils. Pakistan J. Nutr. 7, 278-282. http://doi.org/10.3923/pjn.2008.278.282

Siger A, Nogala-Kalucka M, Lampart-Szczapa E. 2008. The content and antioxidant activity of phenolic compounds in cold pressed plant oils. J. Food Lipids 15, 137-149. http:// dx.doi.org/10.1111/j.1745-4522.2007.00107.x

SPSS. 1994. SPSS Professional Statistics (Version 10,1). SPSS Inc., Chicago, USA

Steenson DF, Lee JH, Min DB. 2002. Solid phase microextraction of volatile soybean oil and corn oil compounds. J. Food Sci. 67, 71-76. http://dx.doi.org/10.1111/j.1365-2621.2002. tb11361.x

Strecker LR, Bieber MA, Maza A, Grossberger T, Doskoczynski WJ. 1996. Corn Oil, in Hui YH (Ed.). Bailey's Industrial Oil and Fat Products. Wiley, New York, 125-158. ISBN13: 978-0471594307 / ISBN-10: 047159430X
TGK. 2002. Turkish codex standard for determination of the maximum limits of definite contaminants in foods. Codex number 2002/63. Ankara, Turkey

Tuan HQ. 2011. Characterization of natural edible oils regarding their quality and safety related constituents. Master Thesis, Division of Food Chemistry, Department of Food Sciences and Technology, University of Natural Resources and Life Sciences, Vienna, Austria

Tuberoso CIG, Kowalczyk A, Sarritzu E, Cabras P. 2007. Determination of antioxidant compounds and antioxidant activity in commercial oilseeds for food use. Food Chem. 103, 1494-1501. http://dx.doi.org/10.1016/j. foodchem.2006.08.014

Yılmaz E, Arsunar ES, Aydeniz B, Güneşer O. 2015a. Cold Pressed capia pepperseed (Capsicum annuum L.) oils: composition, aroma and sensory properties. Eur. J. Lipid Sci. Technol. 117, 1016-1026. http://dx.doi.org/10.1002/ ejlt.201400276

Yilmaz E, Aydeniz B, Güneser O, Arsunar ES. 2015b. Sensory and physico-chemical properties of cold press produced tomato (Lycopersicon esculentum L.) seed oils. J. Amer. Oil Chem. Soc. 92, 833-842. http://dx.doi.org/10.1007/ s11746-015-2648-x

Yılmaz E, Öğütcü M, Arifoglu N. 2015c. Assessment of thermal and textural characteristics and consumer preferences of lemon and strawberry flavored fish oil organogels. J. Oleo Sci. 64, 1049-1056. http://dx.doi.org/10.5650/jos. ess 15113 